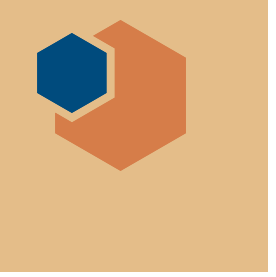

\section{Materials to play vital role in US-India solar technology consortium}

www.seriius.org

$\mathbf{T}$ o expand clean energy research, development, and deployment, the United States (US) and India announced plans in 2010 for a USD $\$ 125$ million Joint Clean Energy Research and Development Center (JCERDC). In April 2012, the US and India announced lead institutions for consortia in each of JCERDC's three focus areas of solar technology, building efficiency, and advanced biofuels. Research and development work, much of which will advance materials research in solar technology, is expected to begin this fall.

Each consortium has an institutional lead in India and in the US, as well as multiple university, national laboratory, and private industry partners. The gov- ernments of India and the United States have each pledged USD $\$ 5$ million per year for five years to the JCERDC effort in their own country, pending appropriations. Consortia members are providing an additional USD \$75 million in matching funds.

The solar technology consortium, named the Solar Energy Research Institute for India and the United States - or SERIIUS-will be led in India by the Indian Institute of Science-Bangalore (IISc) and in the US by the National Renewable Energy Laboratory (NREL). SERIIUS aims to develop and ready emerging revolutionary solar electricity technologies in order to help India meet its Jawaharlal Nehru National Solar En-

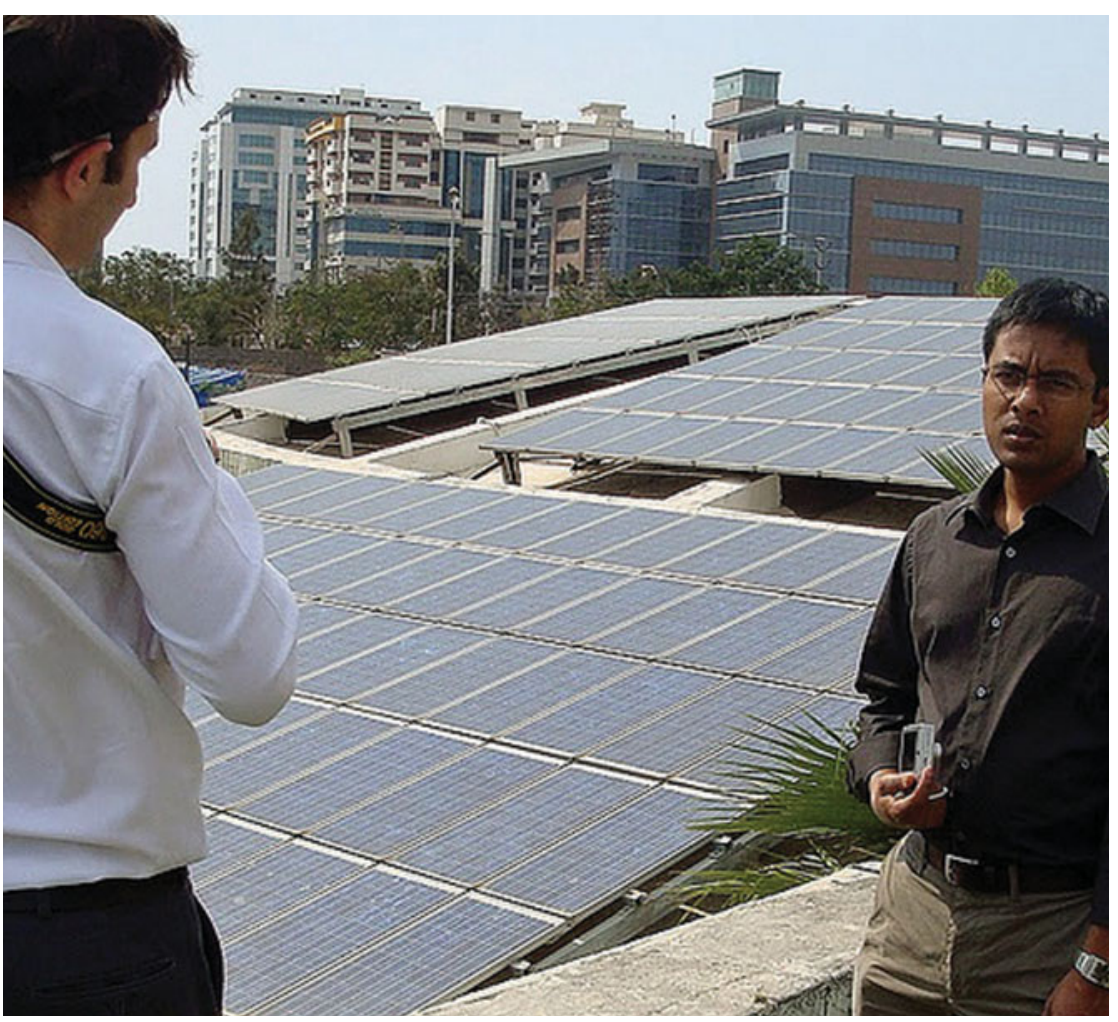

Solar panels on the roof of the Confederation of Indian Industry's Godrej Green Business Center in Hyderabad. Credit: Natural Resources Defense Council

ergy Mission, which includes installing 20,000 MW of solar grid power by 2022 as one of its goals, and to support the US Department of Energy (DOE) SunShot Initiative, whose goal is to reduce the cost of installed solar-energy systems by $75 \%$ by the end of the decade.

The SERIIUS team includes nearly 30 collaborators from national laboratories, universities, and private industry. Over the next five years, SERIIUS will invest more than USD $\$ 58$ million in its mission to advance solar energy technology, USD $\$ 25$ million shared equally by the US and India, pending appropriations, and the remainder in matching funds from consortium members.

To help the two countries meet their solar energy goals, SERIIUS is focusing on three research thrusts: sustainable photovoltaics (PV); multiscale concentrated solar power; and integrating solar energy into India's technical, economic, environmental, and political landscape. The overarching goal of the project is to quickly lower the cost per watt of power in support of the national solar energy plans, according to NREL's Larry Kazmerski, who co-directs the center along with IISc-Bangalore's Kamanio Chattopadhyay.

Kazmerski said, "SERIIUS positions the technical communities of our two countries to strengthen these national programs. But it also revolutionizes the way we approach research with truly collaborative, jointly led research and development. The accomplishments will be greater than what could result from individual efforts alone."

Materials will play a key role in the work of this consortium, with this new investment helping to address several challenges facing materials research. For example, one of SERIIUS's primary objectives related to sustainable photovoltaics is to develop new scalable absorbers based on Earth-abundant materials and environmentally friendly processes. This task correlates well to the established basic research needs developed by DOE, especially regarding low-cost photovoltaics, nanostructures for improved solar conversion, and materials by design. 
Similarly, reducing the cost of multiscale concentrated solar power systems and readying them for deployment involves a number of materials challenges, said Kazmerski. For example, SERIIUS members will be exploring innovative designs that use optical materials for solar collectors, novel composite materials for reflectors, and new types of absorber coatings. Many of the planned Indian solar installations are in the Thar Desert of the state of Rajasthan, said Kazmerski, and consequently, mirrors for concentrators and PV module coatings that mitigate dust issues are another important area of study.

General Electric is one of SERIIUS's many industry partners. The company has a strong interest in photovoltaics, concentrated solar power technologies, and power electronics and controls, and joined SERIIUS to take advantage of the collaborative environment. ${ }^{\text {e }} \mathrm{We}$ are acutely aware that the science and technologies in these areas are changing rapidly and we need to develop some of the best scientific networks to gain understanding and stay ahead of the curve. The SERIIUS consortium brings the very best players to the table from both the US and India," said Krishnamurthy Anand, a consulting engineer at General Electric's John F. Welch Technology
Centre in Bangalore.

The building efficiency consortium, named the Center for Building Energy Research and Development (CBERD), will be led in India by the Centre for Environmental Planning and Technology University-Ahmedabad and in the US by Lawrence Berkeley National Laboratory (Berkeley Lab). CBERD will focus on integrating information technology with building controls and physical systems for commercial and high-rise residential buildings, with the end goal of significantly reducing energy use in both countries through collaborative research and promoting clean energy innovation, according to Berkeley Lab's Girish Ghatikar, the US project director. The consortium will expand opportunities for collaboration between researchers and industry, leverage research funding, lead to integrated and proven marketable building technologies, and connect to deployment pathways, said Ashok Gadgil, the US principal investigator for CBERD.

The advanced biofuels consortium will be led in India by the Indian Institute of Chemical Technology-Hyderabad and in the US by the University of Florida. About $95 \%$ of transportation fuel in both the US and India comes from oil. Therefore, advanced biofuels represent a significant opportunity to improve energy security and help India meet its rising demand for freight and passenger vehicles. The consortium will focus on developing and optimizing biofuels from non-food biomass such as sorghum, bamboo, and switchgrass. In addition, the consortium will explore ways to use the waste created during the processes to produce additional bioenergy, fertilizers, and bioplastics.

JCERDC is administered in India by the Indo-US Science and Technology Forum (IUSSTF) and in the US by the DOE. It was created as the research component of the US-India Partnership to Advance Clean Energy (PACE), an initiative launched in November 2009 by India's Prime Minister Manmohan Singh and President Barack Obama. PACE aims to accelerate the transition of each country to high-performing, lowemissions, and energy-secure economies through research and deployment.

For more details on PACE, visit the website of the DOE Office of Policy and International Affairs, http://energy. gov/pi/office-policy-and-international-affairs. Additional information on SERIIUS can be found on the consortium website, http://www.seriius.org.

Kendra Redmond
German National Academy of Sciences Leopoldina issues critical statement on bioenergy www.leopoldina.org

I $\mathrm{n}$ a statement on the opportunities and limits of using bioenergy, the German National Academy of Sciences Leopoldina has come to the conclusion that in quantitative terms, bioenergy plays a minor role in the transition to renewable, sustainable energy sources in Germany at the present time and probably in the future. Bioenergy requires more surface area, is associated with higher greenhouse gas emissions, and is more harmful to the environment than other renewable sources such as photovoltaic, solar thermal energy, and wind energy. In addition, energy crops potentially compete with food crops. The report, released in July, recommends finding strategies for saving energy and increasing energy efficiency in this area.

The Leopoldina's statement "Bioenergy-Chances and Limits" was compiled by a working group of more than 20 expert scientists established in 2010. The report provides recommendations for using bioenergy, defined as energy obtained from the burning of non-fossil plant biomass or biofuels derived primarily from biomass.

The statement also outlines the conditions under which utilization of bioenergy is appropriate and what kind of technologies are currently available or are being developed to convert biomass into biofuels such as bioethanol and biodiesel. In addition, it introduces various scientific approaches aimed at producing hydrogen from water in a sustainable and environmentally friendly manner.

The statement extends earlier Leopoldina reports on the topic of energy: "Concept for an integrated energy research program for Germany" (2009) and "Energy- and research-policy recommendations following the events in Fukushima" (2011).

The report is available as a short version in German and English and as a detailed English version, in which the statements are supported by scientific documentation. Both versions can be accessed at www.leopoldina.org. 